\section{The Millennium Development Goals: taking stock as the first phase ends}

\author{
Nick J Brown, R Mark Beattie
}

In global health terms, the 1980s and 1990s was a period of some turmoil. Funding to the countries we now term 'Low and Middle Income' (LMICs) had become the province of financial institutions like the World Bank and International Monetary Fund (IMF), which filled the vacuum created by the waning enthusiasm of High Income Country governmental development budgets. ${ }^{1}$ This, in turn, wrested autonomy from the LMICs, creating a cycle of dependency. The subsequent insecurity and reluctance to invest in sustainability was compounded by chronic war, famine and instability and, in many parts of Sub-Saharan Africa and South Asia, this resulted in inertia. This was further exacerbated by other issues, some refractory and others new and wholly unexpected: appallingly low literacy rates and refractory gender inequality, the emergence of HIV, the rise of multidrug-resistant tuberculosis, stagnation in the prevention and management of malnutrition, rising antimalarial drug resistance and a limited repertoire of vaccines against the predominant respiratory pathogens.

Against this background, the United Nations met in September 2000 in New York at a meeting attended by all 189 member states of the time. Couched within a sub-section of the aspirational general Millennium Declaration were eight highly ambitious, very specific and timetargeted Millennium Development Goals (MDGs), ${ }^{2}$ arguably the highest profile global health project ever conceived. These were based on a mixture of social, developmental, health, nutrition, water and sanitation determinants. The philosophy was simple: every country member signing the accord would aim to achieve its own target. The targets were largely based on achieving set minimum improvements in each parameter from the 1990 levels by 2015.

Each MDG had (and still has) implications for child health, the first six being most directly related. MDG 1 specifies a

Archives of Disease in Childhood, BMA House, Tavistock Square, London, UK

Correspondence to Dr RM Beattie, Editor in Chief, Archives of Disease in Childhood, BMA House, Tavistock Square, London WC1H 9JR, UK; editor.adc@bmj.com halving of extreme poverty and hunger; MDG 2 the achievement of universal primary education; MDG 3 the elimination of gender disparity; MDG 4 the reduction of child mortality by two-thirds; MDG 5 the reduction of maternal mortality by three-quarters; and MDG 6 the halting and reversal of the rate of spread of HIV and malaria. The final two goals target environmental sustainability: these include access to potable water and adequate sanitation (MDG 7) and working towards global development (MDG 8).

Though each participating country was encouraged to develop initiatives to meet the targets, this would never have been possible without the sort of high income countries/LMIC partnerships envisioned in MDG 8. Fair trade, support of technology and the provision of affordable medicines have all been pivotal. Debt relief has, perhaps, been even more important and the G8 agreement in 2005 to provide major donors such as the World Bank, IMF and African Development Bank the funds to cancel US\$50 billion debt of the most indebted countries such that they could focus on health and development was a major catalyst. In the pre-MDG era, most programmatic work was dichotomised into horizontal (generic delivery using pre-existing infrastructure) or vertical (disease-specific) systems of delivery. The MDG years have seen a shift to mixed systems incorporating both. Successful examples of both include: Integrated Management of Childhood Illness, Global Alliance for Vaccines and Immunisations and the Roll Back Malaria campaign. ${ }^{3}$

Naturally, there have been constraints in implementation, which are both general and specific to each country. These are too numerous to detail here but include social determinants of illness behaviour, inequitable service provision, erratic drug supplies and a paucity of robust tools for quantification.

Over time, a number of valid criticisms have been raised. There is a widespread (though not universal) feeling that the Goals were too narrow, that they failed to target post-primary education, that outcome quantification tools were insufficiently robust and that non-communicable diseases and disability were not included. ${ }^{1}$
There is an additional opinion among some parties that the improvements seen over the period since their implementation would have occurred in any case as a result of concomitant socio-political changes. This may never be fully resolved, but whether or not the association is wholly causal (and allowing for inevitable within country variability), let us examine what has irrefutably changed since the signing of the declaration. Poverty reduction was achieved 5 years ago and the reduction in hunger on course to be achieved in time; $90 \%$ of children in LMICs were receiving at least some primary education in 2010 and in 46 countries at least $30 \%$ of parliamentarians were women; child mortality has fallen by a half from 90 to 46 deaths per 1000 live births from 1990 to 2013, equating to a saving of 17000 lives a day. Maternal mortality has fallen by nearly a half, and $80 \%$ of women receive some antenatal care; HIV and malaria mortality have fallen and antiretroviral treatment is now available to 10 million patients in LMICs. 15

It would be naïve to believe that this is the end of the story and there are a number of reasons for an extension of the project beyond 2015. There remain wide intercountry differences, the poorest nations almost invariably faring worse in their pursuit of the targets, gender inequality has not improved in many parts of the world and children of uneducated mothers are still more likely to die before school age. Many indicators remain off course with, for example, appallingly high stillbirth rates and the continued high prevalence of malnutrition. Stunting, the best composite marker of prenatal, perinatal and postnatal health, remains rife. Primary school education is denied to 1 in 10 children and gender inequality (arguably the least successful of the goals) in many countries is similar to that in 1990 in terms of employment, schooling and authority. These sobering reminders of work yet to do have provided the impetus to new, post-2015 initiatives. ${ }^{5}$ The recognition that work is incomplete has led to a renewal of policy for the next stage, Sustainable Development Goal (SDG) era. Appreciation of the pivotal role of nutrition in all the outcomes has led to a wave of commitment led by the World Health Assembly to both assessment and interventions in the 'first 1000 days'. Other recent initiatives such as the Every Newborn Action Plan and the Global Action Plan for the Prevention of Pneumonia and Diarrhoea (GAPPD) will maintain momentum, but none of these 


\section{Editorial}

will achieve the hoped for advances in the absence of service integration and continued financial support.

It is against this background and with the end of the first phase of the MDGs on the near horizon that ADC commissioned a special supplement to examine the successes, failures and future of the Goals. This is released this month, includes a foreword by HRH The Princess Anne and a series of pieces by very high-profile authors discussing both theme-specific issues and the evolution of child health in each of the world's regions through the MDG era. These issues are relevant to us all, wherever we live and for which we all have a degree of accountability. We are privileged to have assembled a group of such authorities and urge you to read on.
Competing interests None.

Provenance and peer review Commissioned; internally peer reviewed.

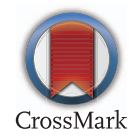

To cite Brown NJ, Beattie RM. Arch Dis Child 2015;100:117-118.

Received 19 November 2014

Revised 1 December 2014

Accepted 6 December 2014

Arch Dis Child 2015;100:117-118.

doi:10.1136/archdischild-2014-307924

\section{REFERENCES}

1 Chopra M, Mason E. Millennium Development Goals: Background. Arch Dis Child 2015;100(Suppl 1): s2-s4.
2 Resolution adopted by the General Assembly [without reference to a Main Committee (A/55/L.2)] 55/2. United Nations Millennium Declaration. http://www. un.org/millennium/declaration/ares552e.htm

3 Travis $\mathrm{P}$, Bennett $\mathrm{S}$, Haines $\mathrm{A}$, et al. Overcoming health-systems constraints to achieve the Millennium Development Goals. Lancet 2004;364:900-6.

4 Yousafzai AK, Lynch P, Gladstone M. Moving beyond prevalence studies: screening and interventions for children with disabilities in low-income and middle-income countries. Arch Dis Child 2014;99: 840-8.

5 The Millennium Development Goals Report 2014. United Nations. http://www.un.org/millenniumgoals/ 2014

6 Harris Reqeujo J, Bhutta ZA. The post 2015 agenda: staying the course in maternal and child survival. Arch Dis Child 2015;100(Suppl 1):s76-s81. 